\title{
resenha bibliográfica
}

Ouchi, William G. Teoria Z: como as empresas podem entrentar o cuesafio japonês. Trad. Auriphebo Berránce Simões. São Paulo, Fundo Eúcativo Brasileiro, 1982. Brochura, sumário, índice analítico, bibliografia. $X I 1+293 p$.

Ouchi conseguiu entrar no Brasil na lista de best-sellers (campeões de vendagem) com sua obra que procura explicar o que os japoneses têm que os norte-americanos não possuem, como características pessoais e de trabalho. Para isso, o autor entra não só num estudo administrativoprodutivo-comparativo, mas também apresenta estudos sobre hábitos, traços sociais e étnicós que moldam o caráter de um e outro povo. Se estamos em presença de estudos científicos sociais de um nivel de Margaret Mead ou de um Seleções do Reader's Digest não cabe a este resenhista decidir. Para exemplificar: o japonès é colaborador, porque o arroz tem de ser cultivado em grupos, - solo é valioso, assim as casas estão uma em cima da outra nos vilarejos; - norte-americano é individualista, porque as fazendas do meio-oeste distam trềs ou mais quilômetros uma da outra, e no inverno năo é possivel recorrer ao vizinho, porque à distância soma-se a neve. De qualquer maneira, todas as justificativas são interessantes, fáceis de serem entendidas e lidas; quanto à sua profundidade politico-social não há necessidade de pesquisar, pois a teoria serve para decidif como o norte-americano deve se comportar para igualar-se ao japonês.

\section{O sumário é o seguinte:}

Parte 1 - Aprendendo com o Japão. Introdução: Por que precisamos aprender?

Capítulo 1: O que podemos aprender?

Capítulo 2: O funcionamento de uma empresa japonesa
Capítulo 3: Comparação entre empresas japonesas e norte-americanas. Capítulo 4: A organização $Z$

Parte 2 - Fazendo funcionar a teoria $Z$

Capítulo 5: De A a Z - os passos.

Capítulo 6: De A a Z - esquemas para uma filosofia.

Capítulo 7: Quem tem sucesso? Algumas histórias de casos $Z$

Capítulo 8: Uma cultura Z

Conclusã̃o: A sobrevivência do empreendimento AMERICANUS

Apêndices: Filosofias de Companhias $Z$

$\mathrm{O}$ círculo $\mathrm{C}-\mathrm{O}$
$\mathrm{Na}$ orelha do livro encontra-se a seguinte informação: "O Dr. Ouchi obtéve seu grau. de mestrado em administração de empresas na Stanford University e o doutoramento na Universidade de Chicago. Atualmente, é professor na Graduate School of Management na Universidade da Califórnia, em Los Angeles."

A passagem de Ouchi pela Universidade de Stanford deve ter dado origem a suas menções de McGregor com $X$ e $Y$, e ao quadro da p. 59 , chamado "O constraste"

Este quadro foi publicado há alguns anos no boletim que é remetido aos antigos alunos da Stanford Gra. duate School of Business Administra-
Organizações japonesas

1. Emprego vitalício

2. Avaliação e promoção lentas

3. Trajetorias de carreira nãoespecializadas

4. Mecanismos de controle implícitos

5: Tomada de decisão coletiva

6. Responsabilidade coletiva

7. Interesse holistico (do todo).
Organizações norte-americanas

1. Emprego a curto prazo

2. Avaliação e promoção rápidas

3. Trajetórias de carreira especializadas

4. Mecanismos de controle explícitos

5. Tomada de decisão individual

6. Responsabilidade individual

7. Interesse segmentado tion, entre os quais se encontra o resenhista. A tabela enumerava os contrastes e as semelhanças da teoria de McGregor ( $X$ e $Y$ ) com aquilo que se supunha ser a base do procedimento japonês naquela época. Ouchi, subseqüentemente, deve ter reavaliado McGregor, a quem faz rápida menção no livro presente, sem maior ênfase na semelhança da teoria $Y$ com o que propõe.

Uma das grandes contribuições de Ouchi é a parte 1, na qual, por exemplo, se encontra - fato de que somente $35 \%$ dos japoneses têm a estabilidade (presumida) de emprego nas grandes empresas, o elitismo ine: rente ao preparo das crianças para entrar nas escolas, do jardim de infân: cia até a universidade, e a existêmcia (como em todo o mundo, socialista ou capitalista) de universidades de elite que abrem as portas do empre. go. Também trata do fato de aposentadoria no Japăo ocorrer aos 55 anos, provocando a necessidade de pessoal nåo vinculado as grandes empresas viver com os filhos. 0 autor nấ diz, mas para mim isso significa que no Japão a aposentadoria deve ser in- suficiente para uma vida digna na veIhice, como também em muitos ou. tros países.

O resenhista foi informado por um formado pela Universidade de Tóquio (superelite) que Ouchi filho de japoneses, nascido nos Estados Unidos - é fluente em japonês, o que deve ter melhorado sua sensibilidade e facilidade de acesso às fontes japonesas, comparado com Athos e Pasquale. $E$ isso se nota na parte 1. Considero a descrição da maneira como o trainee no Japão entra em rodízio entre as diversas seções uma fascinante diferença do trainee norteamericano. 0 primeiro passa por tantas seções quantas tiver a empresa, aparentemente e lentamente. 0 segundo passa o suficiente para ser apresentado, para conhecer o que faz. Ouchi frisa que daí vêm os japoneses generalistas e os norte-americanos especialistas - derivando uma estrutura de organização industrial baseada na colaboração e na competição.

O norte-americano entra na empresa comó especialista, após sair de outra, no mesmo lugar, produzin- 
do imediatamente. $O$ japonês não sai, conhecendo na estrutura todo mundo e todos os ofícios. O norte-americano então é avaliado pela produção, objetivamente, como especialista; o japonês, como pessoa humana, subjetivamente.

Neste ponto, tenho uma das maiores críticas ao livro. Na Alemanha o "aprendiz" passa pelos mesmos estágios que o trainee japonês, sendo treinado em toda empresa - e talvez seja de interesse aqui uma apresentação a que assisti numa grande empresa germano-brasileira: "O $\mathrm{Sr}$. Diretor Fulano, um aprendiz nosso", disse o apresentador, "o Sr. Vice Presidente, um aprendiz de nossa matriz, o Diretor de Produção, um aprendiz de nossa matriz e $0 \mathrm{Sr}$. Di. retor Comercial, um APRENDIZ (nome do concorrente na Alemanha) e mesmo assim", prosseguiu o apresentador, "um bom homem". Essa identificação do homem com a carreira, a "tolerância" para com o estranho, é simplesmente desconhecida para Ouchi - e apesar disso, a Alemanha sofre tanto quanto os Estados' Unidos com o Japão. Na Alemanha atendem círculos REFA parecidos com os CQ, los japoneses, mas a diferença persiste. E a REFA antecede com suas reuniões a 1920 . Algo, portanto, falta ao livro de Ouchi. Acredito que a falha está numa visão mais larga do problema; o Japão tem disciplina, colabora porque é útil e antes de tucio é, nas palavras de Carl Rogers, centrado na pessoa e não na atividade, característica alemå e norte-americana.

- Ouchi falha, na minha opinião, quando não considera a ausência de pressão e tempo no Japão, no desenvolvimento de produtos ou nas meIhorias (simplificação) do trabalho; também devia levar em conta 0 empréstimo feito pelos bancos, com juro subsidiado, e a fundo perdido, eventualmente, para 0 desenvolvimento de produtos, ou melhoria de procedimentos. Mas, considerada como um todo, a parte 1 é muito boa.

Na parte 2, a implantação da teoria Z, o autor começa a falhar, pois quando um professor dá receituário industrial ele entra. em área escorregadia, isto é, lugares-comuns patinam pelas páginas. Inicialmente, uma verificação sem.cura: a empresa $Z$ (e a japonesa) tem mais preconceitos que as outras - são contra estra- nhos (xenofobia, como dis Ouchi). E, assim, nada de mulheres, negros etc. em empresas Z. A minoria não se entende, não entra em consenso, complica, em uma palavra, a vida.

Agora, na parte 2, prefiro dar algumas das conclusões para demonstrar minha tese de que analisar é mais fácil que aconselhar.

1. Compreender a organização $Z$ e o seu papel - desenvolver a confiança dos outros.

2. Dar respostas integradas aos problemas (the big picture, na Harvard).

3. Fazer auditoria da filosofia de sua empresa.

4. Definir a filosofia de administração desejada e envolver o líder da empresa.

5. Implantação da filosofia pela criação de estruturas e incentivos.

6. Desenvolver habilidades interpessoais - escutar mais do que falar.

7. Reconhecer padrões de interação.

8. Dar incentivos não-monetários e monetários, tipo plano Scanlion (mutual Mears).

9. Usar o método científico - testar a si mesmo e ao sistema. Usar auditor ou observador.

10. Envolver o sindicato.

11. Estabilizar o emprego.

12. Decidir-se por um sistema de promoção e avaliação lentas.

13. Ampliar ao desenvolvimento e a trajetória da carreira.

14. $\mathrm{Na}$ implantaçăo começar por baixo (operário). ( (vide General Motors).

15. Procurar áreas para implantar participação.

16. Permitir o desenvolvimento de relacionamentos holísticos.

É empresarialmente possível fazer tudo acima, mas um leve odor de déjà vu invade essa parte do livro e de bons conselhos, afinal, se nutri. ram todos os sistemas administrativos desde que entrei no campo, em 1954 - desde o TWI (Training Within (ndustry) até a administração por objetivos (que procurava envolver a todos).

Ouchi proćura tornar paralela a boa administração lou a melhor administração norte-americana IBM, Exército, Hewlett-Packard etc.) ao trátamento de pessoal o mais aproximado ao japonês. $O$ fato é que a última parte do livro é dedicada ao "credo" da Hewlett-Packard e de outras empresas, e assim, de pa. ralelo em paralelo, chega-se ao uso da teoria $Z$ nos Estados Unidos. Essa parte, de casos práticos, é de fácil leitura e interessante - mas nada tem de extraordinário, isto é, corresponde ao ordinário, ou o comum, nas empresas bem administradas. Talvez o caso da General Motors seja o mais extenso, mas o conteúdo é incidental, quando um autor escolhe casos para mostrar algo deve informar se existem casos contra. E isso não acontece. Encontramos até alguns conceitos estranhos: em lugar de APO (Administração por Objetivos) - livro nos leva à APD (Administração por Deslocamentol, isto é, o gerente, ou quem for, se desloca fisicamente para a área-problema (pôr a mão na massa). O sistema parece estranho, pois caso a individuo tenha de resolver simultaneamente mais de um problema precisa deslo. car-se de seção para seção.

Em resumo, Ouchi escreveu um liv,ro interessantíssimo, meio pesquisa fascinante, meio conselhos acadêmi. $\cos$, de utilidade, que faz pensar, e que, de qualquer maneira, deve ser lido, e que dará, senão uma melho. ria de produtividade, ao menos uma satisfação de entender melhor o que faz funcionar o Japão de hoje.

\section{Kurt Ernst Weil}

Professor titular no Departamento de Administração da Produção de Operações Industriais (POI, da EAESP) FGV 